This document is confidential and is proprietary to the American Chemical Society and its authors. Do not copy or disclose without written permission. If you have received this item in error, notify the sender and delete all copies.

\title{
Inorganic Cyanide as Protecting Group in the Stereospecific Reconstitution of Vitamin B12 from an Artificial Green Secocorrinoid
}

\begin{tabular}{|r|l|}
\hline Journal: & Organic Letters \\
\hline Manuscript ID & ol-2016-02611f.R1 \\
\hline Danuscript Type: & Communication \\
\hline Complete List of Authors: & $\begin{array}{l}\text { Prieto, Lucas; University of Zurich, Department of Chemistry } \\
\text { Neuburger, Markus; University of Basel, Department of Chemistry } \\
\text { Spingler, Bernhard; University of Zürich, Department of Chemistry } \\
\text { Zelder, Felix; University of Zuerich, Inorganic Chemistry }\end{array}$ \\
\hline
\end{tabular}

SCHOLARONE ${ }^{\text {Ix }}$

Manuscripts 


\title{
Template for Submission of Manuscripts to American Chemical Society Journals
}

\author{
Word 2010, Page Wide Abstract Version
}

This template is a guide to be used to prepare manuscripts for submission. Please consult the Instructions to Authors or a recent issue of the journal for detailed guidelines and procedures for submission. This template is intended to benefit to the author in that the entire manuscript (text, tables, and graphics) may be submitted in one file. Inserting graphics and tables close to the point at which they are discussed in the text of the manuscript can also be a benefit for the reviewer.

When you submit a manuscript using this template, you will not actually see the page formatting that appears in the printed journal. This will occur as part of the editorial production process. Abbreviated instructions for using the template follow. Consult the documentation for your specific application and version for more information. Additional instructions can be found in the readme file at the web page where you downloaded this template.

\section{Using the template}

In ACS publications there are many different components of a manuscript (i.e., title, abstract, main text, figure captions, etc.) that are represented in the template. See the Guide, Notes, Notice, or Instructions for Authors on the journal's homepage to determine which parts should be included for the manuscript that you are preparing

1. If typing your manuscript directly into the template, select (highlight) the text of the template that you want to replace and begin typing your manuscript (i.e., select the Title section for typing in your title).

2. If you have already prepared your document in a Word file, you will need to attach the template to your working document in order to apply the Word Style tags. Further instructions can be found in the readme file at the web page where you downloaded this template.

a. Go to the Word Style list on the formatting toolbar and you will see all the Word Styles from the template that has now been imported into the current document. A Styles toolbar has been generated that will display the different Styles for you to choose from. If this is not present, select View, Toolbars, and then select Styles and it should appear. You can close this at any time and then reopen it when needed.

b. Click in the sentence or paragraph and then go to the Word Style menu on the toolbar and select the relevant Word Style. This will apply the Word Style to the entire text (sentence or paragraph). Do this for all sections of the manuscript.

3. To insert graphics within the text or as a figure, chart, scheme, or table, create a new line and insert the graphic where desired. If your graphic is not visible, ensure that the Word Style is "Normal" with an automatic height adjustment. If the size of the artwork needs to be adjusted, re-size the artwork in your graphics program and repaste the artwork into the template (maximum width for single-column artwork, $3.3 \mathrm{in} .(8.5 \mathrm{~cm})$; maximum width for double-column artwork, 7 in. $(17.8 \mathrm{~cm}))$. NOTE: If you are submitting a Table of Contents graphic, please insert the graphic at the end of the file.

4. Ensure that page numbers are present on all pages before submitting your manuscript.

5. Delete these instructions and any sections that are not needed.

6. Save the file with the graphics in place: select Save As (File menu) and save it as a document file (not a .dot template file).

7. Proof the manuscript to ensure that all parts of the manuscript are present and clearly legible. 
Vitamin $\mathrm{B}_{12}$ (" $\mathrm{B}_{12}$ ", 1, Figure 1) and $\mathrm{B}_{12}$ cofactors represent the most complex non-polymeric natural products ${ }^{1}$ combining uniquely a central cobalt ion with a highly decorated corrin macrocycle. $^{2}$ Their nature, structure, chemistry and enzymology have inspired scientists for decades and $B_{12}$ research contributed significantly to the advancements in natural sciences in the last century. ${ }^{1 \mathrm{~b}, 3}$

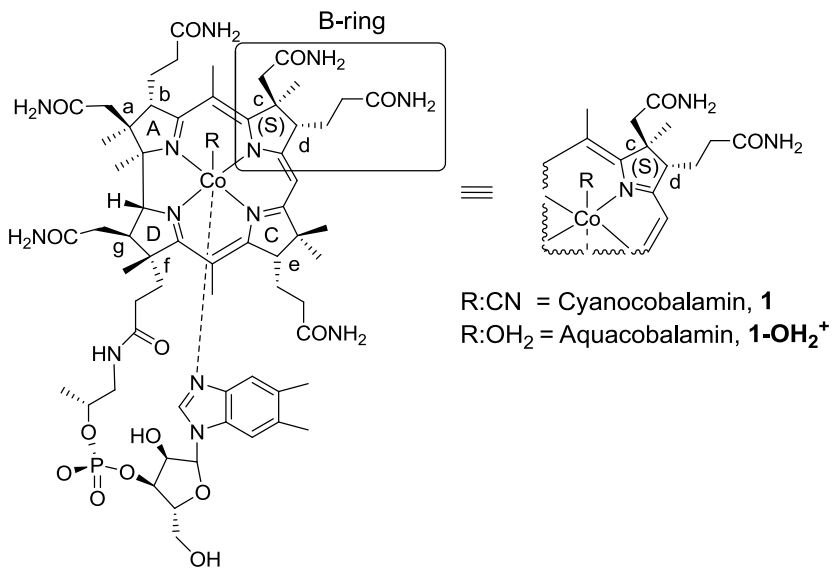

Figure 1. Structural formula of cob(III)alamins: cyanocobalamin $\left(\mathbf{1}\right.$, vitamin $\left.\mathrm{B}_{12}, \mathrm{R}=\mathrm{CN}\right)$, aquacobalamin $\left(\mathbf{1}-\mathbf{O H}_{2}{ }^{+}\right.$, vitamin $\mathrm{B}_{12 \mathrm{a}}$, $\mathrm{R}=\mathrm{H}_{2} \mathrm{O}$ ) highlighting the B-ring area (in bracket) and its schematic representation.

The total synthesis of vitamin $\mathrm{B}_{12}$ by the groups of Eschenmoser and Woodward is considered as one of the milestones in natural product synthesis for which the development of ingenious novel bond forming reactions and synthetic methodologies were required. ${ }^{4}$ To name a few,
Eschenmoser and his group developed during the first total synthesis of $\mathrm{B}_{12}$ the sulfide contraction reaction for joining two halves of the corrin macrocycle together in a metal-templated reaction. ${ }^{5}$ Later, photochemical ring closure reactions were introduced for the challenging direct $\mathrm{C}-\mathrm{C}$ coupling reaction between rings $\mathrm{A}$ and $\mathrm{D}$ of the corrin macrocycle. ${ }^{6}$ Inspired by these important pioneering studies and recent progress in the field, ${ }^{7}$ we herein report the unprecedented stereospecific reconstitution of vitamin $B_{12}$ in 4 steps from an artificial 'green 'secocorrinoid ${ }^{8}$ with a $\mathrm{C}-\mathrm{C}$ bond forming radical key reaction using inorganic cyanide as metal-ion protecting group. In this reaction, the stabilization of the +III oxidation state of the cobalt centre with two axially coordinating cyanide ligands was essential for achieving chemoselectivity in the ligand-centered reduction of the $\mathrm{Co}^{\mathrm{III}}$-containing octahedral complex. $^{9}$

The radical C-C bond forming reaction between $\mathrm{C} 8$ and $\mathrm{C} 7$ of a secocorrinoid was first described by Kräutler and coworkers for converting a 'blue ${ }^{-}$secocorrinoid ${ }^{10}$ into a $B_{12}$ derivative with an intact corrin macrocycle (Scheme 1, top). ${ }^{7}$ Unfortunately, the configuration of the c-acid side chain at $\mathrm{C} 7$ of the reaction product was inverted compared to $\mathrm{B}_{12}$, making further transformations of the epimer to the natural product unfeasible. We speculated whether reconstitution of secocorrinoids to vitamin $B_{12}$ would be principally possible with other derivatives and tested therefore the green 7,8-secocorrinoid 2 (Scheme1, bottom). ${ }^{8}$ We were optimistic since ${ }^{1} \mathrm{H}$ ${ }^{1} \mathrm{H}$ ROESY experiments showed correlations between $\mathrm{H}_{\mathrm{C} 7 \mathrm{~A}}$ and both $\mathrm{H}_{\mathrm{C} 4 \mathrm{~N}}$ and $\mathrm{H}_{\mathrm{C} 10 \mathrm{~N}}$ of this derivative (Scheme 2), suggesting that $\mathrm{C} 7 \mathrm{~A}$ is directed to the lower $(\alpha)$ site of the secocorrinoid and thus representing the same orientation as 
Scheme 1. (Top) Schematic representation of the conversion of blue 7,8-seco-corrinoid to $\mathrm{Co}_{\beta}$-cyano- $\mathrm{B}_{\beta}$ hydroxy-7-epicobalamin-c-acid. (Bottom) Conversion of green 7,8-seco-corrinoid to vitamin $\mathbf{B}_{12}$. Previous work ${ }^{[7]}$

to von-natural configuration
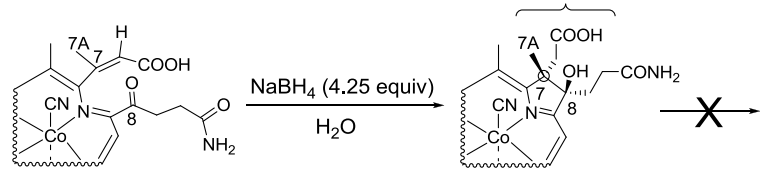

Blue 7,8-seco-corrinoid $\mathrm{Co}_{\beta}$-cyano- $8_{\beta}$-hydroxy7-epicobalamin-c-acid

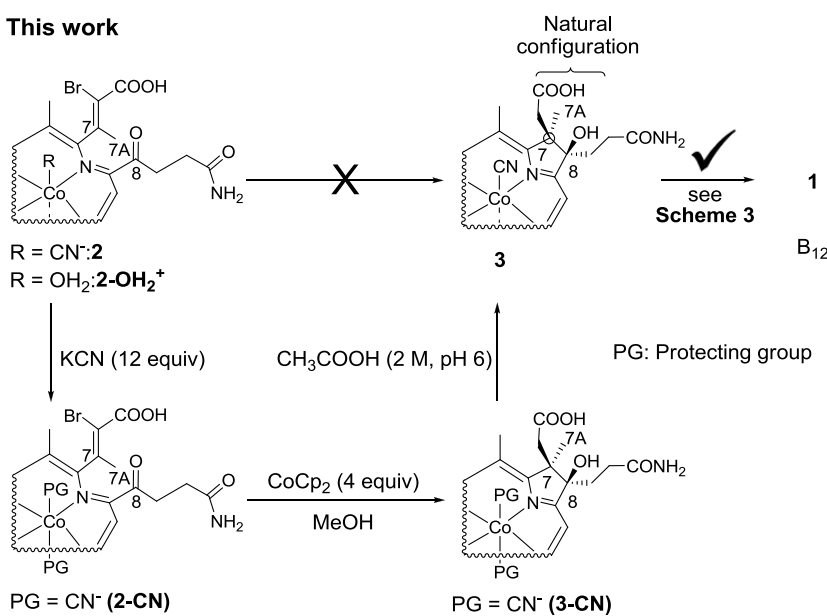

observed in $\mathrm{B}_{12}{ }^{8}$ For triggering the intended radical ring closure between $\mathrm{C} 7$ and $\mathrm{C} 8$ of $\mathbf{2}$, consisting of a $\mathrm{C}-\mathrm{C}$ coupling and a subsequent bromine elimination, we applied the oneelectron donor cobaltocene $\left(\mathrm{CoCp}_{2}, \mathrm{E}=-0.750 \mathrm{~V}\right.$ vs. $\mathrm{Ag}^{+} / \mathrm{AgCl}$ in $\left.\mathrm{MeOH}\right)^{11}$ in the reaction. However, only metalcentered reduction of $\mathrm{Co}^{\mathrm{III}}$ to $\mathrm{Co}^{\mathrm{II}}$ was observed for 2 , leading finally to $\mathbf{2 -} \mathbf{O H}_{2}^{+}$after reoxidation of the pentacoordinated cob(II)alamin with air (Scheme S1). ${ }^{12}$ The observed metalcentered reactivity is in line with the behavior of $\mathrm{B}_{12}$ yielding $\mathrm{OH}_{2} \mathrm{Cbl}\left(\mathbf{1}-\mathbf{O H}_{2}{ }^{+}\right)$under the same reaction conditions (Scheme $\mathrm{S} 2$ ). In order to achieve chemoselective reduction of the macrocyclic ligand at its C8 position, we transformed 2 with an excess of cyanide to the dicyanospecies $\mathbf{2 - C N}$ (Schemes 1, 2). Advantageously, such an axially coordinating cyanide ligand is easily introduced and can also be selectively removed from the metal center under slightly acidic conditions. ${ }^{13}$ Importantly, the dicyano-Co ${ }^{\text {III }}$ derivative $\mathbf{2 - C N}$ contains a less reduction sensitive $\mathrm{Co}^{\mathrm{III}}$ center compared to $\mathbf{2}$. Indeed, the strongly $\delta$-donating cyanide ligand shifts the reduction potential of cob(III)alamins to more negative values (approximately $400 \mathrm{mV}$ ) and thus stabilizes the $\mathrm{Co}^{\text {III }}$-ion against reduction. $^{9 \mathrm{~b}, 14}$ This behavior should render ligandinstead of metal-centered reductions of $\mathbf{2 - C N}$ more likely, but has not yet been so far exploited for synthetic purposes. In fact, control experiments revealed that violet dicyanoB $B_{12}$ (1CN) did not show any colour change in the presence of cobaltocene (Scheme S3). After having proven the inertness of $\mathrm{Co}^{\mathrm{III}}$ in dicyanocob(III)alamins under reductive conditions, the reactivity of 2-CN was tested in the presence of cobaltocene (Schemes 1, 2, S4). To our delight, the dark green solution turned violet within seconds. The immediate appearence of the typical colour of a dicyanocob(III)alamin species suggested reconstution of the corrin macrocycle and excluded any coincidental reduction of the $\mathrm{Co}^{\mathrm{III}}$ center to a brown $\mathrm{Co}^{\mathrm{II}}$ derivative. ${ }^{15}$ The UV-Vis spectrum of $\mathbf{3 - C N}$ resembled closely that of dicyanocob(III)alamin 1-CN. MS analysis of the reaction mixture suggested conversion of $\mathbf{2 - C N}$ to $\mathrm{Co}_{\beta}$-cyano8 -hydroxy-cobalamin-c-acid $\left(3-\mathbf{C N} ; \mathrm{m} / \mathrm{z}=698.4,[\mathrm{M}-\mathrm{H}]^{2-}\right)$. ${ }^{1} \mathrm{H}$ NMR analysis of the crude base-on compound 3 after removal of the cyanide protecting group (Scheme 1, Figure 2) showed excellent agreement with the spectrum of $\mathrm{B}_{12}(\mathbf{1})$, exhibiting only significant differences in chemical shifts at the B-ring of the macrocycle as well as at $\mathrm{C} 4 \mathrm{~N}$ of the dimethylbenzimidazole nucleobase (Figure S4-6, Table S1). In particular, 3 lacks a signal at $3.46 \mathrm{ppm}$ of the $\mathrm{C} 8-\mathrm{H}$ proton of 1 and the corresponding ${ }^{13} \mathrm{C}$ signal was shifted downfield by 30 ppm (88.2 ppm in $\mathbf{3}$ vs. $58.2 \mathrm{ppm}$ in $\mathbf{1}$ ). Moreover, the ${ }^{1} \mathrm{H}$ NMR analysis univocally shows that $\mathbf{3}$ was formed as a single diastereoisomer in the reaction. The orientation of the c- and $\mathrm{d}$-side chains of $\mathbf{3}$ was first tentatively assigned based on the reactivity of $\mathbf{3}$ under acidic conditions. Quantitative conversion to a new species with a pseudo molecular ion at $\mathrm{m} / \mathrm{z}=1354.6\left([\mathrm{M}+\mathrm{H}]^{+}\right)$was observed, that is 18 units less than the molecular mass of $\mathbf{3}$. We assumed the formation of a $\mathrm{c}$ lactone between the c-monocarboxylic acid and the 8-hydroxo group of the B-ring for explaining the structural change (Scheme 3). Importantly, such an intramolecular reaction is only possible for steric reasons if both functionalities are pointing towards the same side of the molecule.

Scheme 2. Schematic representation of the proposed radical triggered reconstitution of the $\mathrm{B}$-ring of 3-CN using inorganic cyanide as a metal-ion protecting group (intermediate A). Dotted lines in 2 indicate ${ }^{1} \mathrm{H}-{ }^{1} \mathrm{H}$ ROESY interactions.

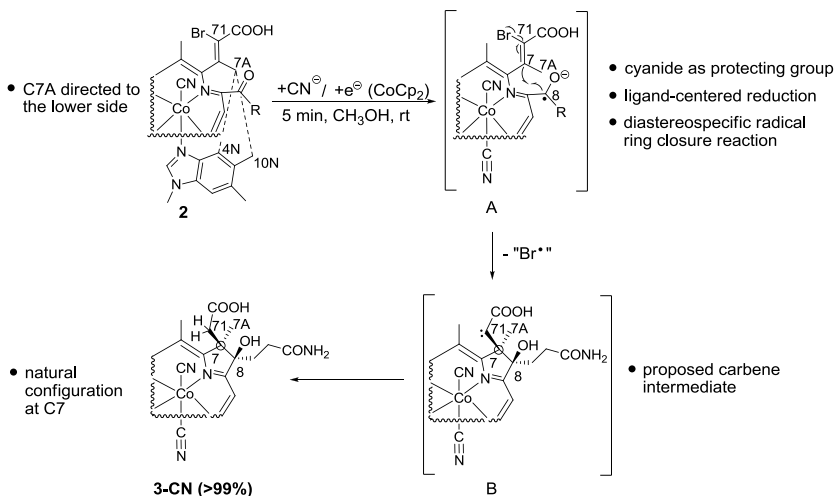

For evaluating the orientation of the c-lactone moiety in the reconstituted compound, we compared its analytical data with that of CNCbl-c-lactone 4 (Figures S7-9). The latter contains a c-lactone moiety attached to the upper side of the B-ring of the corrin macrocycle and was synthesized independently from $\mathrm{B}_{12 .}{ }^{16}$ In brief, all analytical data of the reconstituted compound and $\mathbf{4}$ were identical, indicating strikingly that the c-lactone functionalities are directed to the same side of the molecule. In turn, this means for the reconstituted compounds 3 and 4 that the c-acetic acid functionalities at $\mathrm{C} 7$ are orientated upwards and the propionamide moieties at $\mathrm{C} 8$ to the lower side of the molecule. To our delight, this behavior reveals that the side chains located at the periphery of the Bring of the reconstituted compounds exhibit the same orientation as in $\mathrm{B}_{12}$. The diastereospecific nature of the ring closure reaction is probably best rationalised by a highly preorganised arrangement of $\mathrm{C} 7, \mathrm{C} 7 \mathrm{~A}$ and $\mathrm{C} 8$ in the secocorrinoid 2 for the $\mathrm{C}-\mathrm{C}$ bond forming reaction (Scheme 2 ). ${ }^{8}$ In particular, the reaction is initiated by the formation of highly reactive $\mathrm{C} 8$ centered radical (intermediate A; Scheme 
2) that combines then rapidly and diastereospecifically with the short-distanced C7 under the mild reaction conditions. The existence of intermediate A (Scheme 2) was supported by radical scavenging experiments. Indeed, only starting material was observed by UPLC-MS when the reduction of $\mathbf{2 - C N}$ with cobaltocene was attemped in the presence of the radical scavenger TEMPO (see supporting information). However, in the absence of this inhibitor, C-C coupling occurs and it is suggested that this reaction is accompanied by the elimination of a bromine radical from $\mathrm{A}$ originating the carbene intermediate B. The latter incorporates finally two hydrogens from $\mathrm{MeOH}$ leading to reconstituted 3.

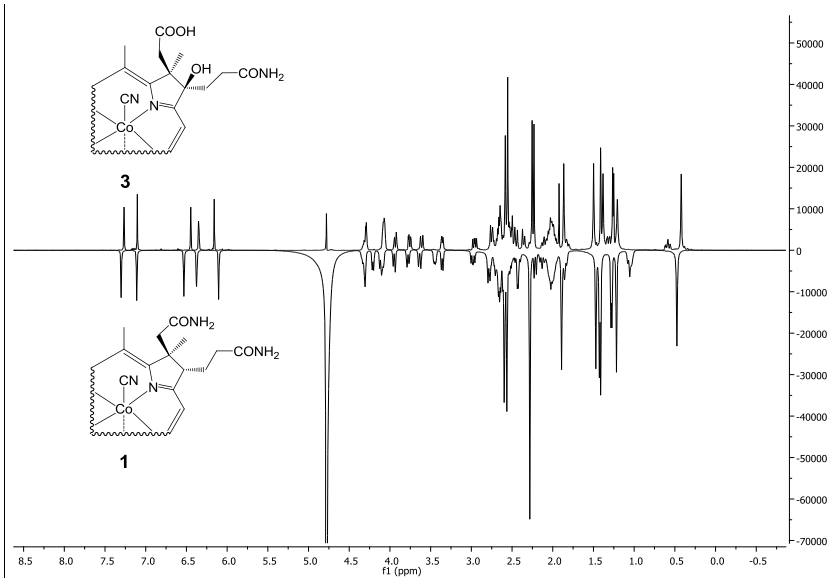

Figure 2. ${ }^{1} \mathrm{H}-\mathrm{NMR}$ spectra of $\mathrm{Co}_{\beta}$-cyano- $8_{\beta}$-hydroxy-cobalaminc-acid (3, top $)$ and cyanocobalamin $\left(\mathrm{B}_{12}, \mathbf{1}\right.$, bottom $)$.

Having CNCbl-c-lactone (4) in hand allowed us now to devise a straightforward route to vitamin $\mathrm{B}_{12}$ in two steps. ${ }^{17}$ Reductive ring opening of $\mathbf{4}$ with $\mathrm{NaBH}_{4}$ afforded CNCbl-cacid (5) that was finally converted with $\mathrm{N}$-(3dimethylaminopropyl)- $N$ '-ethylcarbodiimide hydrochloride (EDC) and ammonium chloride to CNCbl (1) (Scheme 3).

Scheme 3. Reconstitution of vitamin $B_{12}$ (1) from 3 .

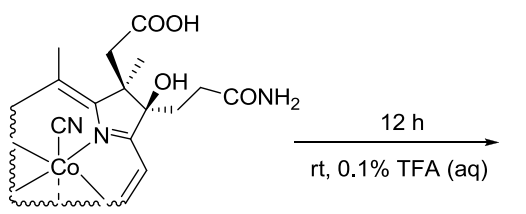

3

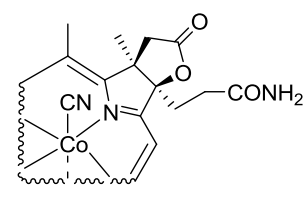

$\mathrm{NaBH}_{4}, 30 \mathrm{~min}$ $\mathrm{rt}, \mathrm{H}_{2} \mathrm{O}$
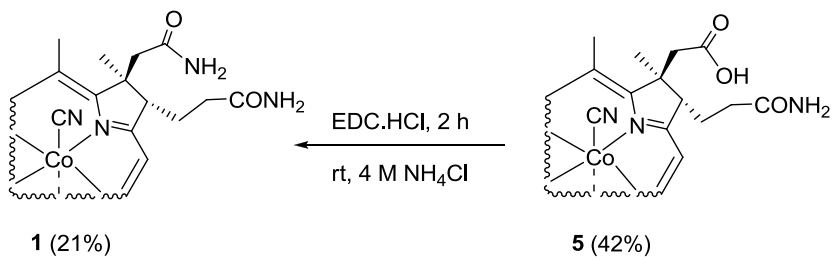

The analytical data of the reconstituted and microbially produced vitamin $B_{12}(\mathbf{1})$ are identical. Single crystals of the reconstituted compounds $\mathbf{5}$ and $\mathbf{1}$ (both synthesized starting from 2) were grown by vapour diffusion of acetone into an aqueous solution of either $\mathbf{1}$ or $\mathbf{5}$, and $\mathrm{X}$-ray analysis confirmed definitely the natural configuration of all side chains of the reconstituted products. As the crystals were weakly diffracting on a molybdenum source and X-ray fluorescence using copper radiation was observed, we finally measured both crystals with the help of a gallium source (see Supporting Information for more details). Figure 3 top shows the overlay of $\mathbf{1}$ (blue) and $\mathbf{5}$ (normal element colours) and Figure 3 bottom the overlay of $\mathbf{1}$ (normal element colours) and a reference structure of vitamin $\mathrm{B}_{12}$ (red). ${ }^{18}$

Being confident about the structural integrity of reconstituted $\mathbf{1}$, its function was evaluated in a microbiological assay using Lactobacillus leichmannii. ${ }^{19}$ This bacterium requires cofactor $\mathrm{B}_{12}$ for ribonucleotide reductase as the only $\mathrm{B}_{12}$ dependent enzyme. ${ }^{19-20}$ Bacterial cell growth was strongly increased in the presence of nanomolar concentrations of reconstituted $\mathbf{1}$ and its biological activity was identical to that of the microbially produced natural product (Figure S19).
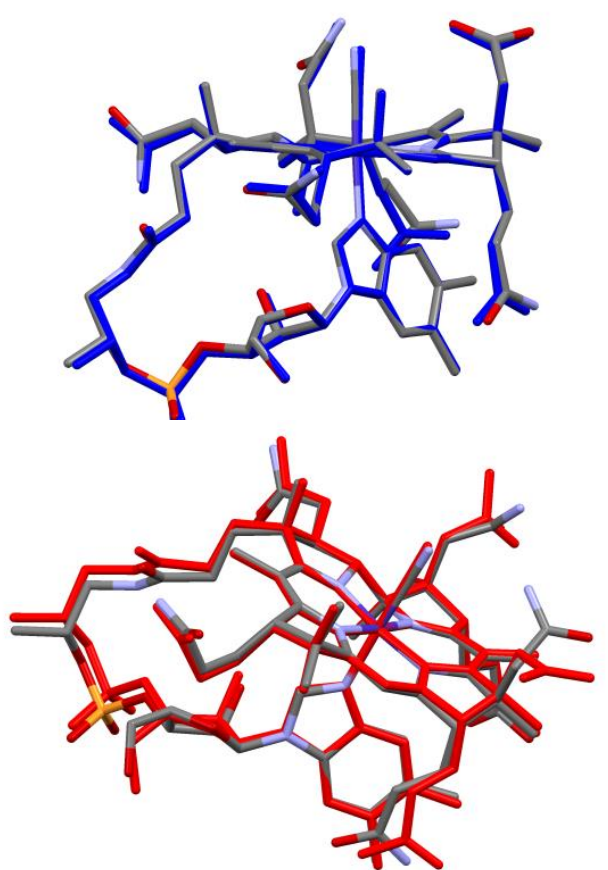

Figure 3. Top: overlay of the X-ray structures of $\mathbf{1}$ (blue) and $\mathbf{5}$ (normal element colours). Bottom: overlay of $\mathbf{1}$ (normal element colours) and a reference structure of vitamin $\mathrm{B}_{12}$ (red). ${ }^{18}$

In contrast, the novel reconstituted $\mathrm{Cbl}$ derivative $\mathbf{3}$ with an acetate functionality at $\mathrm{C} 7$ and an alcohol group at $\mathrm{C} 8$ behaves differently than $\mathrm{B}_{12}$ and shows antivitamin activity in the $\mathrm{B}_{12^{-}}$ dependent growth of L. Leichmannii. In particular, 50\% inhibition was observed with antivitamin $3(1 \mu \mathrm{M})$ in the presence of $\mathrm{B}_{12}(0.1 \mathrm{nM})$ (Figure 4$)$. 


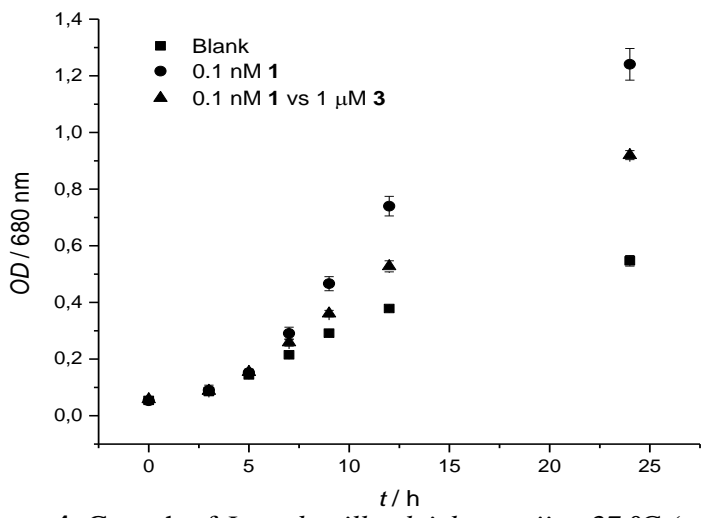

Figure 4. Growth of Lactobacillus leichmannii at $37^{\circ} \mathrm{C}(\mathrm{n}=3)$ in the presence of $\mathrm{B}_{12}(0.1 \mathrm{nM})$ and in the presence and absence of antivitamin $B_{12} 3(1 \mu \mathrm{M})$.

These results are inspiring and suggest that this synthetic route can be probably still further exploited for synthesizing even more potent antivitamin $B_{12}$ derivatives, a research field that attracts currently great interest in the community., 19,21

In summary, the unprecedented reconstitution of $\mathrm{B}_{12}$ from an artificial green secocorrinoid is reported. The key step of the route is a stereospecific radical $\mathrm{C}-\mathrm{C}$ bond formation for reconstructing the B-ring of the macrocycle. This rapid and quantitative ring closure reaction was initiated by a oneelectron ligand-centered reduction of the secocorrinoid and leads first to a novel antivitamin $B_{12}$ derivative that is subsequently converted to the final natural product. Chemoselectivity in this transformation was achieved by protecting reversibly the $\mathrm{Co}^{\mathrm{III}}$ center of the precursor with inorganic cyanide against undesired metal-centered reduction.

\section{ASSOCIATED CONTENT}

\section{Supporting Information}

All experimental procedures and complete analytical and biological data of new products is available free of charge via the Internet at http://pubs.acs.org

\section{AUTHOR INFORMATION}

Corresponding Author

*E-mail: felix.zelder@chem.uzh.ch

\section{Author Contributions}

The manuscript was written through contributions of all authors. / All authors have given approval to the final version of the manuscript.

\section{Notes}

The authors declare no competing financial interest.

\section{ACKNOWLEDGMENTS}

The work of the authors was supported by a fellowship of the Forschungskredit of the University of Zurich (UZH) to LP. A generous gift of vitamin $B_{12}$ was obtained from DSM Nutritional Products AG (Basel/Switzerland) and Prof. B. Jaun (retired ETH Zurich). We are thankful to PD Dr. L. Bigler (UZH) for the HR-
ESI-MS measurements. Assistance from Prof. H. Brandl (Department of Evolutionary Biology and Environmental Studies, UZH) in microbiological assays, Dr. T. Fox (UZH) in NMR measurements as well as support by Prof. R. Alberto (UZH) and the Department of Chemistry of the University of Zurich are gratefully acknowledged.

\section{REFERENCES}

1. Hogenkamp, H.P.C. in Chemistry and Biochemistry of B12; Banarjee, R., Ed,; JohnWiley and Sons: New York,1999, p 3-8.

2 . Kräutler, B. in Vitamin B 12 and B 12-Proteins; Kräutler, B.; Golding, B. T.; Arigoni, D., Ed,; John Wiley and Sons: New York, 2008, p 3-43.

3. Zelder, F. Chem. Commun. 2015, 51, 14004-14017.

4. Brown, K. L. Chem Rev 2005, 105, 2075-2149.

5. ó Proinsias, K.; Giedyk, M.; Gryko, D. Chem. Soc. Rev. 2013, 42, 6605-6619.

6. Woodward, R. B. Pure Appl. Chem. 1973, 33, 145-178.

7. Eschenmoser, A.; Wintner, C. E. Science 1977, 196, 14101420 .

8. Nicolaou, K.; Sorensen, E., Classics in Total Synthesis, 1996. 1991.

9. Riether, D.; Mulzer, J. Eur. J. Org. Chem. 2003, 2003, 30-45.

10. Craig, G. W. J. Porphyrins Phthalocyanines 2016, 20, 1-20.

11. Eschenmoser, A. Helv. Chim. Acta 2015, 98, 1483-1600.

12. Eschenmoser, A. Q. Rev., Chem. Soc. 1970, 24, 366-415.

13. Yamada, Y.; Wehrli, P.; Miljkovic, D.; Wild, H.-J.; Bühler, N.; Götschi, E.; Golding, B.; Löliger, P.; Gleason, J.; Pace, B.; Ellis, L.; Hunkeler, W.; Schneider, P.; Fuhrer, W.; Nordmann, R.; Srinivasachar, K.; Keese, R.; Müller, K.; Neier, R.; Eschenmoser, A. Helv. Chim. Acta 2015, 98, 1921-2054

14. Ruetz, M.; Fedosov, S. N.; Kräutler, B. Angew. Chem. Int. Ed. 2012, 51, 6780-6784.

15. Oetterli, R. M.; Prieto, L.; Spingler, B.; Zelder, F. Org. Lett 2013, 15, 4630-4633.

16. Lexa, D.; Saveant, J. M. Accounts Chem Res 1983, 16, 235 243.

17. Sonnay, M.; Fox, T.; Blacque, O.; Zelder, F. Chem. Sci. 2016, 7, 3836-3842.

18. Fedosov, S. N.; Ruetz, M.; Gruber, K.; Fedosova, N. U.; Kräutler, B. Biochemistry 2011, 50, 8090-8101.

19. Ruiz-Sánchez, P.; König, C.; Ferrari, S.; Alberto, R. J Biol Inorg Chem 2011, 16, 33-44.

20. Dereven'kov, I. A.; Salnikov, D. S.; Silaghi-Dumitrescu, R.; Makarov, S. V.; Koifman, O. I. Coord. Chem. Rev. 2016, 309, 68-83.

21. Zhou, K.; Zelder, F. Eur. J. Inorg. Chem. 2011, 53-57.

22. Lexa, D.; Sayeant, J. M.; Zickler, J. J. Am. Chem. Soc. 1980, 102, 2654-2663.

23. Schindler, O. Helv. Chim. Acta 1951, 34, 1356-1361.

24. Bonnett, R. Chem Rev 1963, 63, 573-605.

25. Brown, K.; Zou, X.; Wu, G.-Z.; Zubkowski, J.; Valente, E. Polyhedron 1995, 14, 1621-1639.

26. Mebs, S.; Henn, J.; Dittrich, B.; Paulmann, C.; Luger, P. J Phys. Chem. A 2009, 113, 8366-8378.

27. Zhou, K.; Oetterli, R. M.; Brandl, H.; Lyatuu, F. E.; Buckel, W.; Zelder, F. ChemBioChem 2012, 13, 2052-2055.

28. Larsson, K.-M.; Logan, D. T.; Nordlund, P. ACS Chem. Biol. 2010, 5, 933-942.

29. Zelder, F.; Sonnay, M.; Prieto, L. Chembiochem 2015, 16, 1264-1278.

30. Kräutler, B. Chem. Eur. J. 2015, 21, 11280-11287.

31. Vitamin B12 und verwandte Corrinoide; Friedrich, W., , Ed,: Georg Thieme Verlag: Stuttgart, 1975.

32. Chrominski, M.; Lewalska, A.; Gryko, D. Chem. Commun. 2013, 49, 11406-11408. 


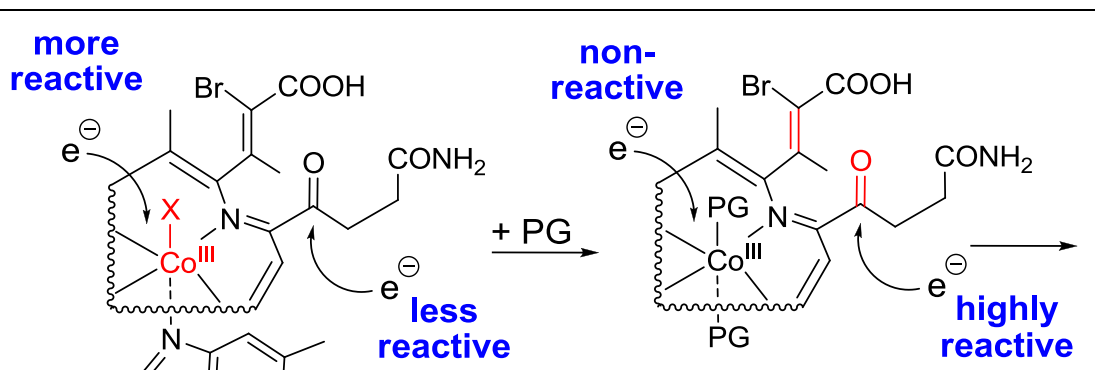

antivitamin $B_{12}$

2

ctive

$\mathrm{COOH}$

- ligand-centered reduction

- chemoselective

- diastereospecific

- quantitative 